\title{
Using Microscopy to Find Stardust Anywhere
}

\author{
Jon Larsen ${ }^{1}$, Matthew Genge ${ }^{2}$ and Jan Braly Kihle ${ }^{3}$ \\ 1. Project Stardust, Oslo, Norway \\ 2. Department of Earth Science and Engineering, Imperial College London, London, UK \\ 3. Institute for Energy Technology, Kjeller, Norway
}

Micrometeorites (MMs) are alien stones that are everywhere around us [1]. MMs ( 200-400 $\mu \mathrm{m}$ in size) contain stardust older than our Sun and have travelled farther than anything else on Earth. They include matter derived from asteroids and comets, and they hold a wealth of information on the early formation of our solar system. Various example cosmic "spherules" found on Earth are shown in Figure 1(a).

In 2009 a MM literally landed on my table, catching both my attention and intrigue. I became further fascinated by MMs due to an interesting paradox: MMs are the dominant extra-terrestrial material that falls to Earth, yet they cannot be easily found. Historically, MMs could only be found in areas free of any anthropogenic influence, like remote deserts, glaciers and even the Antarctic. MMs fall to Earth at a rate of $\sim 1$ particle per square meter per year. Meteorite hunters have tried to build MM traps, but an ideal trap would need to be the size of a football field and have captured particles over decades.

As it turns out, such ideal traps already exist in populated areas: vinyl-covered flat roofs of decades old buildings with low security walls (Figure 1(b)). In 2010, I began collecting dust samples from roofs, roads and parking lots. Over 6 years, I conducted 1000 field searches in populated areas across 50 countries. Using a Zeiss binocular microscope and a custom-built photo rack, I exhaustively examined and classified thousands of particles by color, size and morphology. Recognizing common shapes for anthropogenic and naturally occurring terrestrial particles, I was able to isolate the best MM prospects. In 2015, working with meteorite researchers, scanning electron microscopy and electron microprobe analysis verified the first MM found in a populated area: a $270 \mu \mathrm{m}$ barred olivine (similar example in Figure 2(a)). Verification and classification of MMs [2] requires careful consideration of particle morphology, composition (chondritic composition [3] example in Figure 2(a)) and microstructure (like magnetite dendritic formation shown in Figure 2(b)). Eventually, 500 MMs were classified [4].

In 2017, I authored and published the book, "In Search of Stardust: Amazing Micrometeorites and Their Terrestrial Imposters." This book is a collection of hundreds of example particles, including both urban MMs as well as various example anthropogenic and terrestrial particles [1]. My extensive travels and interactions with fellow meteorite enthusiasts propelled me to start Project Stardust [5], where amateur MM hunters can document their field search and the use of optical/electron microscopy to identify and analyse MMs. With a broom, a bag, a magnet and a microscope, you can truly find stardust anywhere!

\section{References:}

[1] J Larsen, "In search of stardust: amazing micrometeorites and their terrestrial imposters", (Voyageur Press, Minneapolis, MN).

[2] MJ Genge, C Engrand, M Gounelle and S Taylor, Meteoritics \& Planetary Science 43 (2008), p. 497.

[3] DE Brownlee, B Bates and L Schram, Meteoritics \& Planetary Science 32 (1997), p. 157.

[4] MJ Genge, J Larsen, M Van Ginneken and MD Suttle, Geology 45 (2017), p. 119.

[5] J Larsen, Project Stardust, https://www.facebook.com/micrometeorites/ 
(a)

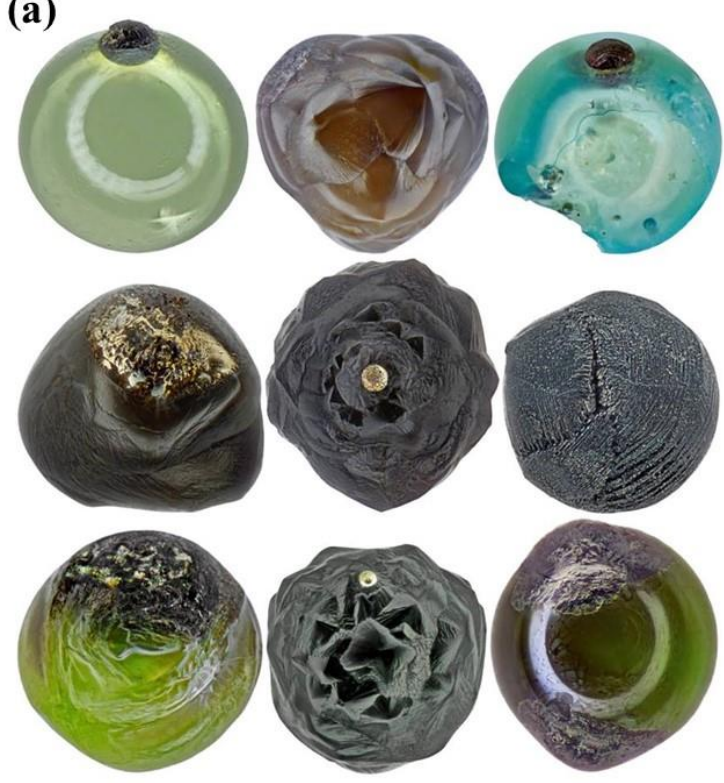

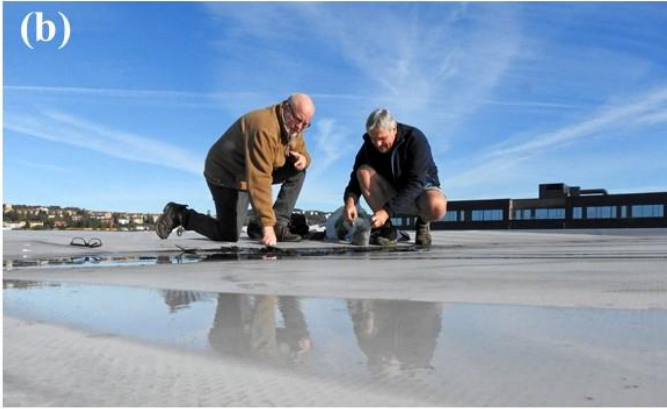

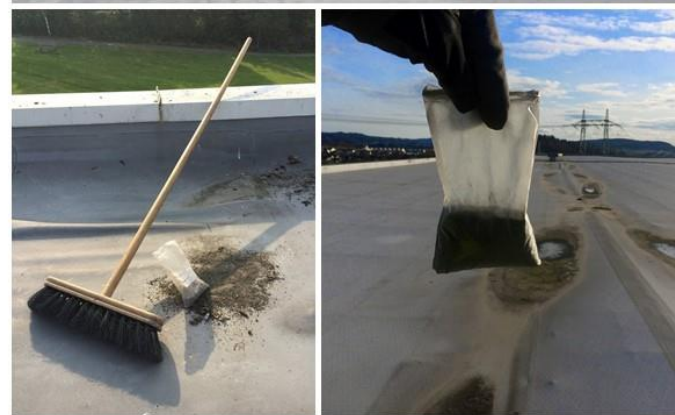

Figure 1. (a) Optical micrographs (OMs) of nine example micrometerorites (MMs): Upper-left - glass / Upper-middle - cryptocrystalline / Upper-right - glass / Middle-left - cryptocrystalline and glass / Middle-middle - cryptocrystalline / Middle-right - barred olivine / Lower-left - porphyritic / Lowermiddle - cryptocrystalline / Lower-right- glass. (b) Photographs of Jon Larsen (right) with Morten Bilet conducting a MM search on the roof of BAMA, Oslo, Norway, with additional photographs of the tools.

(a)

\begin{tabular}{|c|c|c|c|c|c|c|c|}
\hline & $\mathrm{C}$ & $\mathrm{O}$ & $\mathrm{Mg}$ & $\mathrm{Al}$ & $\mathrm{Si}$ & $\mathrm{Ca}$ & $\mathrm{Fe}$ \\
\hline $\begin{array}{l}\text { Example MM weight \% } \\
\text { from Ref. [1] }\end{array}$ & 8.56 & 57.86 & 13.39 & 0.95 & 12.22 & 0.54 & 6.49 \\
\hline $\begin{array}{c}\text { Example } \mathrm{MM} \text { element } / \mathrm{Si} \\
\text { Ratio }\end{array}$ & 0.70 & 4.73 & 1.10 & 0.08 & 1.00 & 0.04 & 0.53 \\
\hline $\begin{array}{l}\text { Antarctic } \mathrm{MM} \text { element } / \mathrm{Si} \\
\text { Ratio from Ref. [3] }\end{array}$ & -- & -- & 1.06 & 0.091 & 1.00 & 0.056 & 0.528 \\
\hline
\end{tabular}

(b)

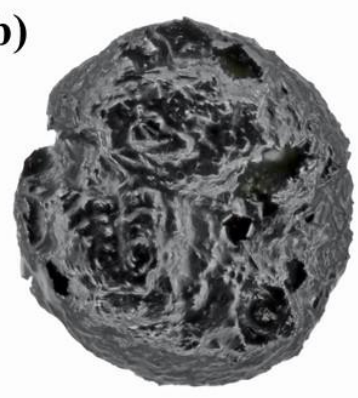

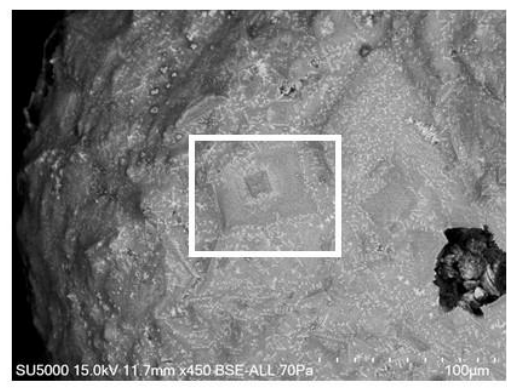

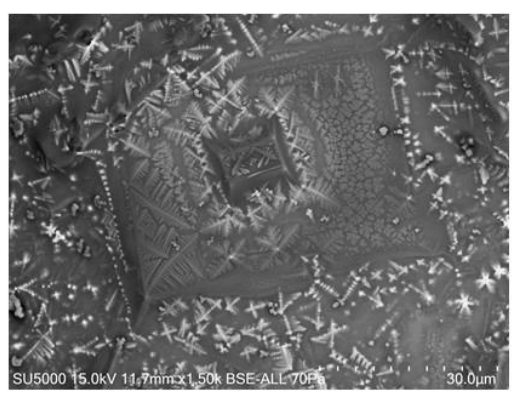

Figure 2. (a) OM of a typical barred olivine MM with a table of EDS-measured elemental composition by weight \% [1] that indicates chondritic composition when compared by element/Si ratios to MMs obtained from the Antarctic [3]. (b) OM of a $~ 700 \mu \mathrm{m}$ porphyritic olivine MM found at Nesodden, Akershus, Norway, with BSE micrographs indicating dendritic magnetite formation (bright features). 